Review Article

\title{
Biological Functions of Diallyl Disulfide, a Garlic-Derived Natural Organic Sulfur Compound
}

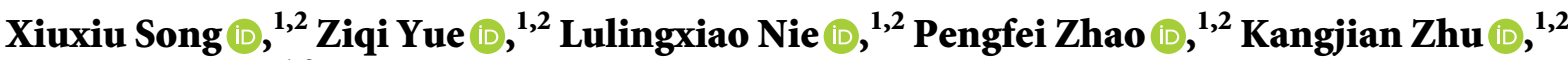 \\ and Qi Wang $\mathbb{1}^{1,2}$ \\ ${ }^{1}$ State Key Laboratory of Oral Diseases, National Clinical Research Center for Oral Diseases, West China Hospital of Stomatology, \\ Sichuan University, Chengdu, China \\ ${ }^{2}$ Department of Prosthodontics, West China Hospital of Stomatology, Sichuan University, Chengdu, China
}

Correspondence should be addressed to Qi Wang; wqinno8751@gmail.com

Received 19 April 2021; Revised 15 August 2021; Accepted 6 October 2021; Published 29 October 2021

Academic Editor: Alessandra Durazzo

Copyright (C) 2021 Xiuxiu Song et al. This is an open access article distributed under the Creative Commons Attribution License, which permits unrestricted use, distribution, and reproduction in any medium, provided the original work is properly cited.

Garlic is widely accepted as a functional food and an excellent source of pharmacologically active ingredients. Diallyl disulfide (DADS), a major bioactive component of garlic, has several beneficial biological functions, including anti-inflammatory, antioxidant, antimicrobial, cardiovascular protective, neuroprotective, and anticancer activities. This review systematically evaluated the biological functions of DADS and discussed the underlying molecular mechanisms of these functions. We hope that this review provides guidance and insight into the current literature and enables future research and the development of DADS for intervention and treatment of multiple diseases.

\section{Introduction}

Plants are excellent sources of pharmacologically active ingredients. Garlic has been commonly accepted as a functional food and traditional herb for the prevention and treatment of several diseases, especially cancer and infectious diseases [1-4]. It is believed that organic sulfur compounds are responsible for most of the biological activities of garlic [5]. Diallyl disulfide (DADS; structure: two sulfur atoms with two allyl groups; see Figure 1) is a major organosulfur compound of garlic [6,7]. Studies have shown that DADS has many biological functions, including antiinflammatory, antioxidant, anticancer, and detoxifying effects, which may be determined by its chemical structure [4, 7-9]. Previous reviews have discussed the promising value of DADS in the prevention and treatment of a wide range of diseases [6]. In this work, we performed a systematic review of the biological functions of DADS based on the cellular and molecular mechanisms, hoping to provide an updated scientific basis and insight for future experiments.

\section{Methodologies}

We made a search in PubMed, Web of Science, and GeenMedical up to June 2021 for the existing literature on DADS. We also searched the International Clinical Trials Registry Platform and ClinicalTrials.gov for potentially relevant clinical trials. References of included papers and reviews were manually searched to make a supplement.

\section{Biological Functions of DADS}

3.1. Anti-Inflammatory Activity. Inflammation is an adaptive response of the host to adverse stimuli such as trauma, toxicity, and microbial infection. A proper inflammatory response can eliminate harmful stimuli and promote tissue healing [10]. However, uncontrolled inflammation leads to sustained damage of the tissues and organs often resulting in pathological changes to these systems [11]. Researchers have reported that DADS can inhibit inflammation in several diseases, such as enteritis, arthritis, and pancreatitis [12-14]. Fasolino et al. [15] demonstrated that edema of the mucosa 


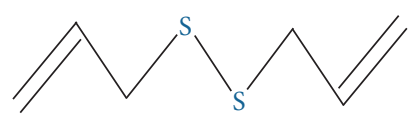

FIgURE 1: Chemical structure of DADS.

and submucosa was significantly reduced in the colon of rats treated with DADS. Furthermore, a low dose of DADS (between 0.3 and $10 \mathrm{mg} / \mathrm{kg}$ ) was observed to suppress increases in the colon weight/colon length ratios that represent dinitrobenzene sulfonate-induced intestinal inflammation/ damage. In a recent animal study, the anti-inflammatory and antioxidant effects of DADS were further confirmed using a carrageenan injection-induced acute inflammatory response mouse paw model [9].

DADS plays an essential role in inflammatory response by modulating immune cells. Hashizume et al. [16] reported that DADS could modulate the circulating number of total lymphocytes, leukocytes, and monocytes in both doseand time-dependent manners. Immune cells usually activate intracellular signaling pathways to respond appropriately to adverse stimuli. One of the most important pathways is the nuclear factor kappa B (NF- $\kappa \mathrm{B})$ signaling pathway. A study showed that DADS attenuated the development of ceruleininduced pancreatitis and its associated lung injury in mice by suppressing the transcriptional activity of NF- $\kappa \mathrm{B}$ p 65 and the degradation of $\mathrm{I} \kappa \mathrm{B}[14]$, which were consistent with other study findings $[17,18]$. Further research revealed that DADS inhibited glycogen synthase kinase (GSK)-3 $\beta$, which suppressed the NF- $\kappa \mathrm{B}$ pathway and further prevented prolonged inflammation, cellular transformation, and tissue damage [19]. DADS affected the expression of signal transducer and activator of transcription 1 (STAT 1), which could inhibit the enhancement of NF- $\kappa \mathrm{B}$ signaling by binding to the target of tumor necrosis factor (TNF)- $\alpha$ [20]. In addition, DADS was shown to suppress the receptor activator of NF- $\kappa \mathrm{B}$ ligand-induced inflammatory osteolysis by inhibiting STAT3 and NF- $\kappa \mathrm{B}$ signaling both in vitro and in vivo [21].

One of the most prominent features of the inflammatory response is the release of inflammatory mediators. One study provided strong evidence that DADS could inhibit the lipopolysaccharide (LPS)-induced production of inducible nitric oxide synthase (iNOS) and cyclooxygenase-2 (Cox-2) in RAW 264.7 cells [22], which thus led to the reduction in $\mathrm{NO}$ and prostaglandin E2 (PGE2) in activated cells [23-25]. Another study on LPS-stimulated neurogenic innate immune cells, BV2 microglia, also found that treatment with DADS significantly inhibited several proinflammatory cytokines and chemokines, including interleukin (IL)-1 $\beta$, IL-6, TNF- $\alpha$, and monocyte chemoattractant protein-1 [26]. Recent studies have further confirmed this physiological effect in animal models of neuroinflammation [27].

3.2. Antioxidant Activity. Antioxidants are substances that prevent, reduce, or repair tissue damage caused by reactive oxygen species (ROS). Over the past two decades, several studies have shown that DADS has a range of antioxidant properties [9, 28-30]. This includes a direct effect on ROS production, which was identified in an in vitro study demonstrating that DADS reduced deoxycholic acid-induced ROS levels in Barrett's epithelial cells when introduced within an effective concentration range [31]. Another study showed that treatment with DADS significantly reduced ROS levels in IL- $1 \beta$-treated bone marrow mesenchymal stem cells [17]. However, Filomeni et al. [32] found that DADS induced oxidative stress in neuroblastoma $\mathrm{SH}$ SY5Y cells, which was consistent with the findings of a study on human lung carcinoma cells [33]. This finding aligned with that of other sulfur-containing compounds from garlic, such as diallyl trisulfide (DATS), which induced the apoptosis of human breast cancer cells through ROS accumulation and inhibited it in high glucose-induced cardiomyocytes by reducing ROS production $[34,35]$. The discrepancies in these studies may be attributed to the specificity of the tumor cells and differences in the therapeutic dosage of DADS employed in each study. A study on PC12 neuronal cells found that treatment with $20 \mu \mathrm{M}$ DADS did not exert any evident effect on cell activity. However, the levels of free radicals and membrane lipid peroxidation increased significantly when these cells were treated with concentrations above $50 \mu \mathrm{M}$. In addition, there was an increased risk for cytotoxicity when $100 \mu \mathrm{M}$ of DADS was administered to these cells [36]. The results of this study were similar to those observed in the neuron cell line, N18D3 [37].

Treatment with DADS can activate antioxidant enzymes, such as glutathione S-transferase (GST), catalase, heme oxygenase-1 (HO-1), and superoxide dismutase, which can convert peroxides into less toxic or harmless substances via oxidation reduction, thereby protecting a wide range of cells and tissues from ROS [30, 38, 39]. Treatment with DADS significantly increased nuclear factor-erythroid-2-related factor 2 (Nrf2) and HO-1 levels in acute ethanol-intoxicated mice, ethanol-induced human normal liver cells [40], and LPS-stimulated RAW264.7 cells [41]. Lee et al. [18] demonstrated that DADS promoted the transcription of antioxidant enzymes by dose-dependently enhancing the stability and nuclear translocation of Nrf2 in the cytoplasm. The effects of DADS on Nrf2 also exerted anti-inflammatory effects by deactivating the redox-sensitive proinflammatory $\mathrm{NF}-\kappa \mathrm{B}$ pathway [42]. In addition, DADS could restore the reduced catalase activity associated with hydrogen peroxide treatment in intestinal porcine epithelial cells [43].

\subsection{Antimicrobial Activity}

3.3.1. Antibacterial Activity. In recent years, antibiotic resistance has become a major health problem. Garlic is believed to be an alternative or complementary medicine for antibiotics owing to its extensive antibacterial properties $[44,45]$. Studies have demonstrated that garlic extracts could weaken the formation of Pseudomonas aeruginosa biofilms and sensitize them to tobramycin and phagocytosis by polymorphonuclear leukocytes [46]. According to further research, DADS reduced the production of virulence factors, such as elastase, pyocyanin, and swarming motility, in Pseudomonas aeruginosa by blocking the inactivation of 
quorum-sensing (QS) genes [47-49]. The anti-QS effect of DADS was also found to inhibit Hafnia alvei $\mathrm{H} 4$ by downregulating the expression of luxI and luxR genes [50]. However, the mechanisms by which QS regulates these functions remain unclear. DADS was reported to prevent methicillin-resistant Staphylococcus aureus infection in diabetic mice [51], inhibit the growth of Escherichia coli as an adjunct of gentamicin [52,53], suppress the activity of Helicobacter pylori both in vitro and in vivo [54, 55], and reduce the pathogenicity of common microorganisms isolated from ear infections [56]. In addition, several recent studies have demonstrated that DADS could modulate the gut microbiota. $\mathrm{H}_{2} \mathrm{~S}$ gas released after treatment with DADS prevented or reversed the naproxen-induced changes in the composition of the intestinal microbiota [57]. According to an in vivo study, when a low dose of DADS was added to the normal diet of mice, the bacterial level of Bacteroides in their intestinal tract decreased, while that of Firmicutes increased [58].

3.3.2. Antifungal Activity. To evaluate the antifungal effect of DADS, Alam et al. [59] administered DADS to mice infected with Candida albicans. They found that the niosomal formulation of DADS markedly decreased the secretion of protease and phospholipase from Candida albicans and increased the survival of the infected animals. DADS was also reported to inhibit the growth of Aspergillus versicolor and its toxic metabolites [60].

3.3.3. Antiviral Activity. The antiviral effect of DADS was first reported in 1993. In this research, DADS inhibited the proliferation of HIV-1-infected cells [61]. In addition, DADS exerted anti-inflammatory and antioxidant effects in a dengue virus study, reducing the symptoms and severity of the disease [62]. In recent reports, garlic has been recommended as a potential medicine for COVID19 based on the findings of several preclinical and clinical studies [63, 64]. In the molecular docking test, garlic essential oil also showed a good inhibitory effect on SARSCoV-2 $[65,66]$. However, it is still unclear whether DADS plays a role in the anti-SARS-CoV-2 effect of garlic, and further studies are needed.

3.4. Detoxification. Numerous studies have shown that DADS can protect organs from the harmful effects of several chemical compounds [4]. For instance, DADS can reduce the hearing loss caused by aminoglycoside drugs [67], attenuate the side effects of gentamicin and cisplatin [67-69], positively affect carbon-tetrachloride-induced hepatic damage $[18,70]$, relieve haemorrhagic cystitis induced by cyclophosphamide in rats [71, 72], decrease cyclophosphamide-induced developmental toxicity [73], and greatly alleviate the methotrexate-induced decline in kidney function and subsequent kidney damage [74].

DADS can promote detoxification of the body, which is believed to be related to the activation of antioxidant enzymes and phase II enzymes via the Nrf2/ARE pathway.
DADS was found to significantly boost the activities of phase II enzymes, including GST, quinone reductase, microsomal epoxide hydrolase, and UDP-glucuronosyltransferase in the liver, intestine, kidney, and lungs [75, 76]. DADS also upregulated the expression of the pi class of GST through JNK/AP-1 and ERK/AP-1 signaling pathways. GST is known to combine with electrophilic compounds in cells to cause detoxification [77].

It has been reported that DADS primarily suppresses the carcinogenic effects of chemical compounds via two mechanisms: the modulation of cytochrome P450 (CYP)dependent monooxygenase to inhibit carcinogen activation and the induction of phase II enzymes to accelerate carcinogen degradation. DADS exerted its anticarcinogenic effect by inhibiting CYP2E1 levels in humans, and CYP2A3 and CYP2A3 levels in rats induced by methyl-n-pentylnitrosamine [78]. Based on animal studies, the administration of DADS to rats through gastric intubation reduced the amount of liver CYP2E1 protein by 25\% [79]. Furthermore, treatment with DADS was found to induce the activation of phase II enzymes by protecting Nrf2 from proteasomal degradation of Keap1 and promoting Nrf2 nuclear accumulation, thereby inhibiting the occurrence of chemicalinduced papilloma in mice [80]. A study showed that DADS inhibited cell proliferation, $\mathrm{G} 2 / \mathrm{M}$ arrest, $\mathrm{H}_{2} \mathrm{O}_{2}$ formation, and DNA damage induced by ben-zo[a]pyrene, thereby inhibiting the occurrence of breast cancer [81]. DADS also inhibited the expression of serotonin $\mathrm{N}$-acetyltransferase genes and proteins, leading to the reduction of $\mathrm{N}$-acetyl-2aminofluorene-DNA adducts, which could reduce the risk of cancer associated with exposure to environmental carcinogens $[82,83]$.

3.5. Cardiovascular Protection. The intake of garlic can effectively reduce the risk factors associated with cardiovascular diseases $[3,84,85]$. Based on existing research, DADS plays a critical role in the cardiovascular protective effect exhibited by garlic, by acting as an angiogenesis inhibitor. Exposure to DADS significantly inhibited the angiogenic differentiation of endothelial cells by reducing the activation of matrix metalloproteinases (MMPs) and the secretion of tissue inhibitor of metalloproteinase-1 in endothelial morphogenesis $[86,87]$. DADS was also found to effectively downregulate both the transcription and expression of vascular endothelial growth factors in HL-60 cells in timeand dose-dependent manners [88, 89]. Increasing evidence suggests that both connexins and gap junctions are involved in cardiovascular diseases [90]. DADS was observed to improve rat liver epithelial cell gap-junctional intercellular communication, regulate vascular smooth muscle cell proliferation, and significantly increase connexin 43 expression, which is very important for maintaining normal vascular function [91, 92]. Furthermore, DADS is an effective agent against atherosclerosis as it can protect lowdensity lipoprotein (LDL) from oxidation and glycation $[93,94]$. DADS also protected endothelial cells from oxidized LDL (ox-LDL) damage by reversing the inactivation of endothelial NOS (eNOS) by ox-LDL [95]. 
DADS induces vasodilation by activating perivascular sensory nerve endings [96]. A recent study found that DADS strongly inhibited angiotensin-converting enzyme, upregulated the expression of prostacyclin and Cox-2 in SVEC410 cells, and reduced the level of ROS, thereby playing a role in vasodilation [22]. According to reports, DADS could downregulate intercellular adhesion molecule-1 and MMP-9 and block the inactivation of eNOS $[95,97]$, which has been demonstrated to relieve pulmonary hypertension [98]. Of note, impaired endogenous $\mathrm{H}_{2} \mathrm{~S}$ production may be one of the mechanisms underlying hypertension. As DADS is an $\mathrm{H}_{2} \mathrm{~S}$-releasing agent, it could be considered a promising drug for the treatment of cardiovascular disease [99].

Various studies have suggested that DADS protects the heart, and treatment with DADS was found to improve cardiac dysfunction by inhibiting death receptor-dependent and mitochondrial-dependent apoptotic pathways and enhancing the PI3K/Akt pathway in diabetic rats [100]. Furthermore, DADS ameliorated myocardial hypertrophy by enhancing the biogenesis and biological function of mitochondria in the rat heart [101]. The mitochondrial lipid peroxidation product, tans-crotonaldehyde, is known to cause myocardial ischemia by damaging mitochondrial genes [102]. However, DADS eliminated the toxic effect of trans-crotonaldehyde by interaction with its $-\mathrm{C}=\mathrm{C}-\mathrm{C}-$ and $-\mathrm{CH}=\mathrm{O}$ groups [103].

3.6. Neuroprotection. Garlic and garlic extracts are believed to provide therapeutic benefits in neurological disorders owing to their antioxidant, anti-inflammatory, and neuroprotective effects $[3,104]$. A recent study found that DADS (40 or $80 \mathrm{mg} / \mathrm{kg}$ ) effectively improved LPS-induced depression-like behaviours in mice, with treatment effects comparable to those of imipramine $(10 \mathrm{mg} / \mathrm{kg})$, a clinical antidepressant [105]. However, in young mice, especially during the neural growth stages, high doses of DADS may adversely affect hippocampal neurogenesis, the proliferation of neural progenitor cells, and neurocognitive functions by regulating ERK and brain-derived neurotrophic factor (BDNF)/cAMP response element-binding protein (CREB) signaling, resulting in significant memory deficits [106]. Besides, another recent animal study has shown that DADS played a role in the inhibition of neuropathic pain via the $\mathrm{H}_{2} \mathrm{~S} / \mathrm{BDNF} / \mathrm{Nrf} 2$ pathway [107].

Several previous studies have suggested that DADS may be an effective drug for the treatment of neurodegenerative disorders, such as Alzheimer's disease (AD). Animal studies have shown that DADS could ameliorate the learning and memory of AD mouse models by increasing the number of hippocampal dendritic spines and synapses [108]. DADS derivatives, $7 \mathrm{k}$ and $7 \mathrm{l}$, inhibited $\mathrm{A} \beta$-induced neuronal cell death and reverse scopolamine-induced cognitive impairment in rats via their antioxidative and metal-chelating effects [109, 110]. Moreover, DADS exerted antiamyloidogenic and anti-inflammatory effects and inhibited conformational alteration in tau protein induced by phosphorylation via the GSK-3 $\beta$ pathway [111]. A clinical trial found that the severity of some neurodegenerative diseases, such as $\mathrm{AD}$, was associated with $\mathrm{H}_{2} \mathrm{~S}$ levels. Therefore, as DADS is an $\mathrm{H}_{2} \mathrm{~S}$ donor; it may play a role in the treatment of $\mathrm{AD}$ [112].

\subsection{Anticancer Activity}

3.7.1. Inhibition of Invasion and Migration. The inhibitory effect of DADS on cancer cell movement and invasiveness is identified to be linked to the enhancement of tight junctions and the decrease in MMPs activity $[113,114]$. Increases in transepithelial electrical resistance confirmed that DADS enhances the tight junctions of human prostate cancer cells [113]. DADS was found to block the migration and invasion of human colon cancer 205 cells by inhibiting the expression of MMP-9, MMP-2, and MMP-7 [115]. Additional evaluations revealed that the effect of DADS on MMPs was regulated through the NF- $\kappa \mathrm{B}$ and PI3K/Akt pathways [116]. Previous studies had shown that DADS could reduce TNF$\alpha$-induced $\mathrm{C}-\mathrm{C}$ motif chemokine ligand 2 release, thereby blocking monocyte recruitment and inhibiting malignant tumor invasion [117, 118].

The prevention of epithelial-mesenchymal transition (EMT) is a new hotspot in tumor metastasis research. Inhibiting Ras-related C3 botulinum toxin substrate (Rac)-1 and $\beta$-catenin expression can inhibit EMT in tumor cells [119]. According to studies by Su et al. [120], DADS suppressed the activities of Racl, $\beta$-catenin, p21 activated kinase-1, and Rho kinase-1, leading to the inhibition of gastric tumor cell growth, invasion, and metastasis. Furthermore, DADS regulated MMP-9 expression and reversed EMT by inhibiting the $\beta$-catenin pathway to reduce breast cancer cell metastasis [121]. Inhibition of the LIMK1-cofilin1 pathway by DADS also inhibited EMT, migration, and invasion of gastric cancer cells, which are closely associated with the formation of invasive pseudopods [122]. Notably, these findings were also confirmed using colon cancer cells [123, 124]. Fibronectin, an extracellular matrix component, also causes EMT in tumors. However, treatment with DADS has been reported to reverse the EMT induced by fibronectin in tumors [125]. The deglycase-1 (DJ-1) protein is another promising target for cancer therapy owing to its roles in invasion, migration, and chemoresistance, and several reports have suggested that inhibition of Src phosphorylation by DADS could downregulate DJ-1 expression, thereby inhibiting leukemic cell migration and invasion [126].

3.7.2. Regulation of Cell-Cycle Arrest. DADS was found to inhibit the proliferation of tumor cells partly because of its ability to reduce the cell ratio in the G1 phase and increase the cell ratio in the G2/M phase [127]. During treatment with DADS, the proportion of G2/M cells increased with increasing concentration and exposure time. Further molecular analysis indicated that the reduced level of cyclin B1, cell division cycle $(\mathrm{cdc}) 25 \mathrm{C}, \mathrm{cdc} 2$, and phosphorylated-cdc2 proteins may have contributed to the blockage of the $\mathrm{G} 2 / \mathrm{M}$ phase in DADS-treated esophageal squamous cell carcinoma cells [128]. Studies have shown that DADS increased the mRNA and protein levels of p21 and p53 in carcinoma cells 
and activated the p53/p21 signaling pathway, thereby inducing cell-cycle arrest and cell apoptosis [128, 129]. A previous study indicated that the ability of DADS to block the cell cycle was also associated with histone acetylation [130]. Further research demonstrated that DADS induced an increase in histone $\mathrm{H} 3$ and $\mathrm{H} 4$ acetylation in the CDKN1A promoter, ultimately leading to an increase in CDKN1A gene expression and $\mathrm{p} 21^{\mathrm{WAFl}}$ protein levels [131]. Moreover, DADS resisted the activation of the G2/M gene damage checkpoints by relying on Mec1 (ATR) and Tel1 (ATM) to inhibit DNA repair, which could improve the efficacy of DNA damage-based cancer therapies [132].

Some garlic extracts, including DADS, exert antimitotic effects by impairing microtubules and hindering the assembly of mitotic spindles. Aquilano et al. [133] reported the obvious loss of the microtubule network, with an irregular accumulation of soluble $\beta$-tubulin and reduction of the cytoskeletal counterpart in neuroblastoma SH-SY5Y treated with DADS. In addition, DADS-derived superoxide was observed to actively participate in the oxidation of actin and tubulin, which eventually led to the breaking of the microfilaments and microtubules.

3.7.3. Induction of Apoptosis and Autophagy. Inducing apoptosis in cancer cells is the main anticancer mechanism employed by most chemotherapeutic drugs [134]. DADSinduced apoptosis was observed to be accompanied by an increase in $\mathrm{Ca}^{2+}$ levels and a decrease in mitochondrial membrane potential. Increased $\mathrm{Ca}^{2+}$ led to the activation of caspase- 3 and the release of cytochrome $\mathrm{C}$ from the mitochondria, resulting in proteolysis and apoptosis [135]. In addition to caspase-3, caspase- 9 and caspase-10 were also activated by DADS [136]. Exposure to DADS increased the expression of p53, p38, and p21; decreased the level of antiapoptotic protein, $\mathrm{Bcl}-2$; and upregulated the levels of the proapoptotic proteins, Bax and Bad [127, 137-139]. Moreover, inhibition of histone deacetylation and the ERK pathway and activation of the SAPK/JNK pathway were also found to influence the proapoptotic effect of DADS in human breast cancer [140]. Several studies have also revealed that treatment with DADS could lead to an increase in ROS levels, resulting in the apoptosis of human leukemia HL-60 cells $[141,142]$. However, cells with an ROS buffer system, such as adenocarcinoma gastric cells (rich in glutathione peroxidase) or copper-overexpressing neuroblastoma cells, were shown to be resistant to DADS treatment $[143,144]$. One animal experiment showed that pretreatment with $10 \mu \mathrm{M}$ DADS resulted in an increase in the radiation sensitivity of HeLa cells and significantly promoted radiation-induced apoptosis. Such findings indicated that DADS is a potential radiosensitive agent for human cervical cancer [145].

In addition to inducing apoptosis, some chemotherapeutic drugs induce autophagy, which is another cell death pathway. Studies have reported that exposure to DADS significantly increased the autophagic flux of RAW264.7 cells, and the effects of DADS on autophagy were likely the result of inhibition of the phosphorylation of mTOR and P70S6k/S6K1 [146]. DADS-induced autophagy increases the death of tumor cells, including leukemia and osteosarcoma cells, by inhibiting the PI3K/Akt/mTOR signaling [147-149]. It has been suggested that histone deacetylase (HDAC) inhibitors also play an antitumor role through autophagy [150]; thus, the inhibitory effect of DADS on HDAC activity may partially induce autophagy. However, there is a paucity of research in the field of DADS-induced autophagy, and more investigations are warranted.

3.7.4. Induction of Cell Differentiation. DADS-induced differentiation of human leukemia HL-60 cells was found to be related to the decrease in DJ-1 and calreticulin (CRT) contents [151]. DJ-1 has been reported to play a role in cell differentiation by acting as a cofactor-binding protein or transcription factor [152]. DADS significantly decreased the expression of cluster of differentiation 33 (CD33) and increased the expression of CD11b by downregulating CRT, ultimately inducing the differentiation of human leukemia HL-60 cells [153]. Furthermore, the DADS-induced reduction of CRT could upregulate the mRNA expression of CCAAT enhancer-binding protein- $\alpha$, thereby affecting cell differentiation [154]. Moreover, treatment with DADS was found to increase the acetylation level of core nucleosome histones ( $\mathrm{H} 3$ and $\mathrm{H} 4)$ and accelerate the differentiation of human leukemia cells $[155,156]$ and liver cancer cells [157].

3.7.5. Effect on Epigenetics. The blocking of normal histone acetylation or abnormal histone acetylation is believed to be the root cause of several cancers. DADS was found to enhance the acetylation of histones $\mathrm{H} 3$ and $\mathrm{H} 4$ in normal colon cells both in vitro and in vivo [158]. Druesne et al. [159] reported that treatment with DADS alone increased the transient acetylation of histone H3K14 in human colon tumor cells. However, unlike in normal colon cells, DADS had no effect on histone $\mathrm{H} 4$ acetylation in colon tumor cells, regardless of the cell culture conditions. Furthermore, DADS induced an increase in histone acetylation of the CDKN1A promoter, which in turn led to an increased level of the $\mathrm{p} 21^{\mathrm{WAF} 1}$ protein; this process is known to inhibit tumor proliferation and induce G2/M phase arrest and apoptosis [160]. Notably, these effects of DADS were only observed at high concentrations. Further research is thus needed to confirm whether the HDAC inhibitory effect of DADS can result in primary anticancer effects when normal human diet doses are administered.

\subsection{Regulation of Metabolism}

3.8.1. Regulation of Glycose Metabolism. Several in vivo studies have shown a dose-dependent increase in blood glucose concentration and free fatty acid levels in rats treated with DADS. Such findings suggest that DADS affects glucose metabolism [161]. However, another study reported that garlic oil, rather than DADS, had beneficial effects on glycemic control in streptozotocin-induced diabetic rats [162]. As a result, the specific effects of DADS on glucose metabolism, under both healthy and diabetic conditions, need to 


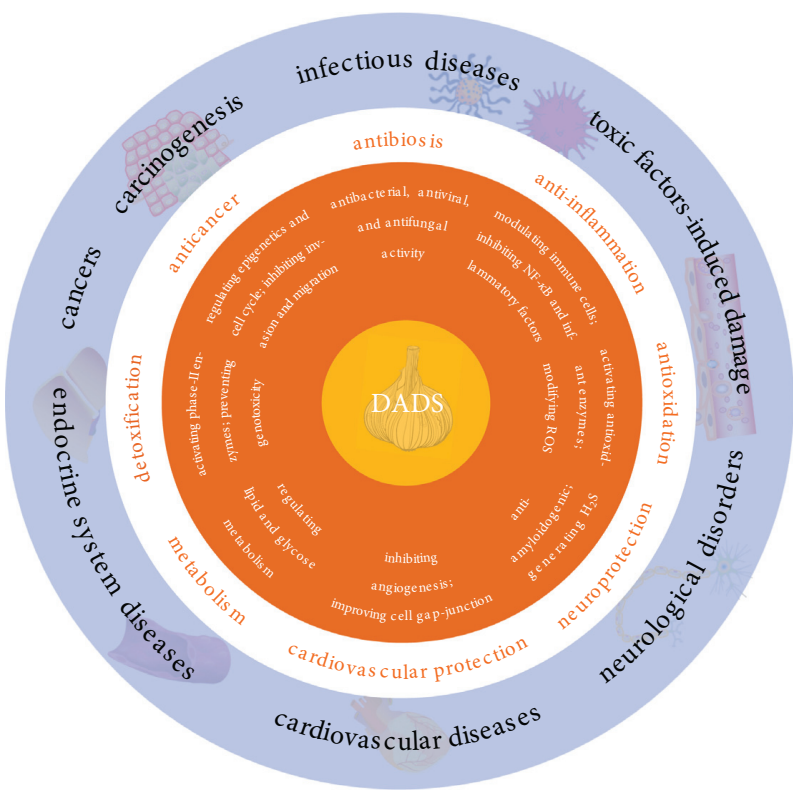

FIGURE 2: Overview of the biological functions of DADS.

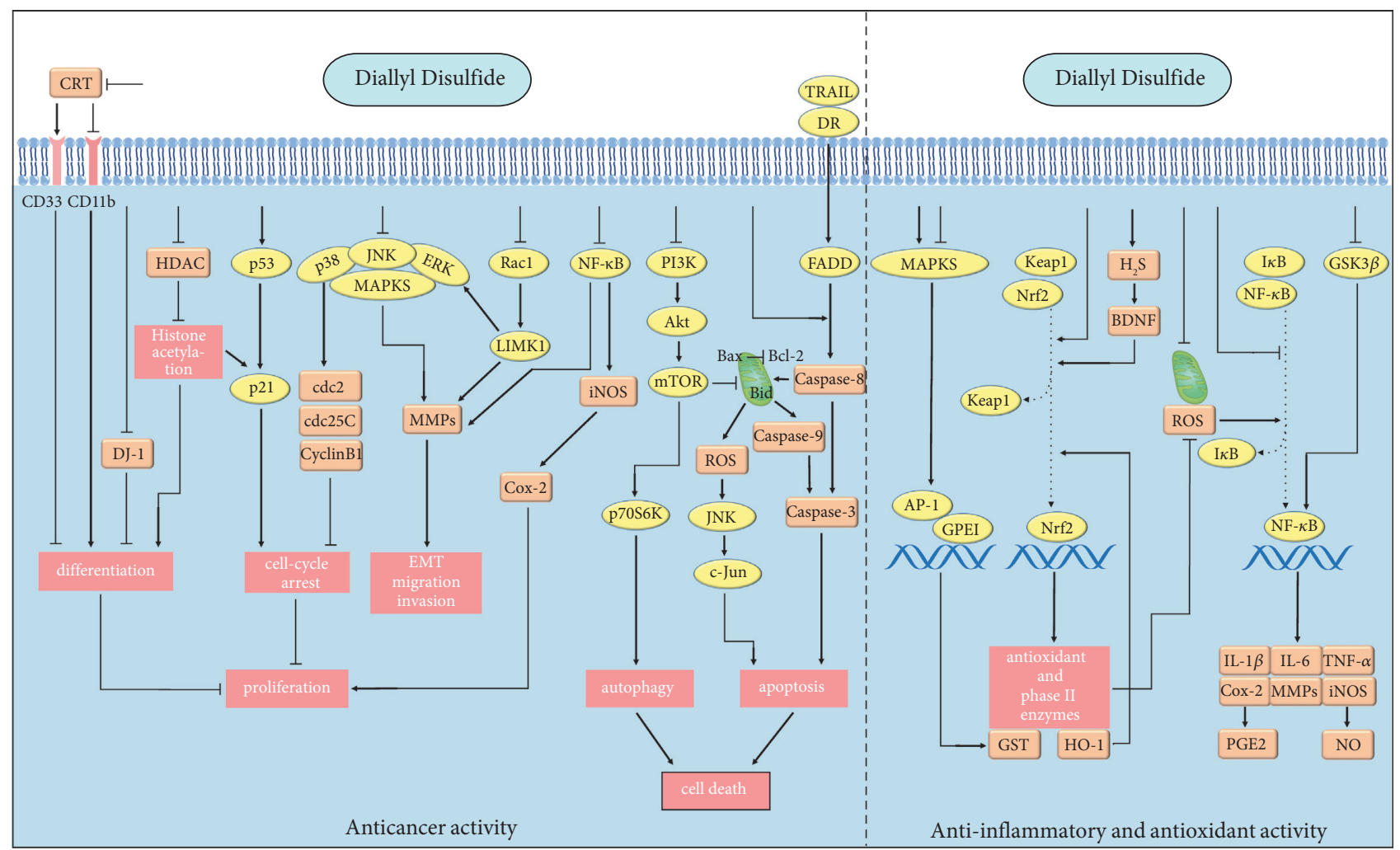

FIgURE 3: The signaling pathways affected by DADS.

be further elucidated. In addition, DADS was observed to suppress glucose metabolism of breast cancer stem cells by inhibiting the CD44/pyruvate kinase M2/AMPK pathway [163].

3.8.2. Regulation of Lipid Metabolism. According to reports, DADS may regulate lipid metabolism by: (a) regulating sterol regulatory element-binding protein-1c, apolipoprotein A1,
CREB-H, and fibroblast growth factor 21; (b) preventing lipotoxicity by increasing peroxisome proliferator-activated receptor- $\alpha$ and inhibiting stearyl coenzyme A desaturase enzyme-1; and (c) significantly inhibiting lipid peroxidation by regulating malondialdehyde and superoxide dismutase [164-166]. Additional studies have reported that the lipid metabolism-regulating activity of DADS may have significant hepatoprotective effects [3]. Additionally, DADS could inhibit 
the accumulation or activation of mesenteric adipose tissue macrophages and the release of monocyte chemoattractant protein-1, suppressing the inflammatory response induced by obesity [167].

3.9. Other Effects. Oral administration of DADS increased the activity of the natural antibody in broiler serum [168]. Moreover, DADS induced chromosome aberration and sister chromatid exchange in the Chinese hamster ovary [169]. DADS could also change iron homeostasis by regulating the expression of ferritin and transferrin receptor genes in hepatocytes in vitro and in vivo [170] (see Figure 2).

\section{Conclusions and Prospects}

DADS, a natural organic sulfur compound, is commonly used as a food additive. Current research suggests that DADS is a promising drug agent for the prevention and treatment of several diseases. This review sought to systematically identify the biological functions of DADS and summarize the underlying molecular mechanisms employed by this compound. The biological functions of DADS can be divided into two categories: the protective effects on normal tissues and the inhibitory effect on disease status. The antiinflammatory and antioxidant effects of DADS are the basis for maintaining tissue homeostasis (such as neurovascular protection and metabolic regulation) and fighting infections (antibiosis). There are interlinks between the anti-inflammatory and antioxidant effects, with NF- $\kappa \mathrm{B}$ and ROS signaling playing key roles. DADS alters the biological properties of cancer cells via specific intracellular and intercellular mechanisms. As a result, DADS exerts significant anticancer effects, such as inducing apoptosis, autophagy, and differentiation. In addition, DADS can also improve efficacy and reduce the negative effects of chemotherapy drugs.

Anti-inflammatory and antioxidant signaling mediators, such as NF- $\kappa$ B, TNF- $\alpha$, ROS, Nrf2, AP-1, JNK, and STAT, play important roles in the biological functions of DADS. Apoptosis and autophagy-associated pathways, such as PI3K, Akt, mTOR, MAPKs, Bcl-2, and Bax, also contribute to the anticancer action of DADS. Notably, the signaling pathways affected by DADS are similar between normal tissue cells and cancer cells. However, different dosages and methods of administration may produce different effects, which requires more experiments to fully verify (see Figure 3).

There are some clinical trials focusing on garlic and its biological effects, including anticancer, anti-inflammatory, antioxidant, and antiviral activities [64, 171-173]. These clinical studies have shown that garlic can be used as an adjunct in the management of several diseases, but with limited effects. Further clinical trials on solitary compounds are necessary to identify the specific active ingredients and thus enhance their medicinal value. Although animal and in vitro experiments have shown that DADS has comparable biological activity with garlic, clinical trials of DADS have not yet been conducted. Therefore, it is still unclear whether
DADS is an active ingredient in the use of garlic in humans and how it exerts its effect. It should be noted that there are some non-negligible issues that need to be solved before conducting clinical trials of DADS. The first is that DADS is rapidly metabolized after being taken into the body and has low bioavailability [6]. The second is the technical difficulties of processing DADS, such as characterization, optimization, and the production of suitable delivery systems [174, 175]. The most important issue is the pharmacokinetic studies of DADS, and its metabolites should be refined. Currently, countries are probing different strategies to prevent and treat COVID-19, which has had a negative impact on global public health and economies. Readily available natural plant products could be a promising starting point for the discovery of new therapeutic drugs. Research on the biological function of DADS may bring us new hope.

\section{Conflicts of Interest}

The authors declare that there are no conflicts of interest regarding the publication of this paper.

\section{Authors' Contributions}

Xiuxiu Song and Ziqi Yue contributed equally to this work.

\section{Acknowledgments}

This research was funded by the National Natural Science Foundation of China (81870779).

\section{References}

[1] D. J. Newman and G. M. Cragg, "Natural products as sources of new drugs over the nearly four decades from 01/1981 to 09/2019," Journal of Natural Products, vol. 83, no. 3, pp. 770-803, 2020.

[2] G. Ekşi, A. M. Gençler Özkan, and M. Koyuncu, "Garlic and onions: an eastern tale," Journal of Ethnopharmacology, vol. 253, Article ID 112675, 2020.

[3] A. Shang, S. Y. Cao, X. Y. Xu et al., "Bioactive compounds and biological functions of garlic (Allium sativum L.)," Foods, vol. 8, no. 7, Article ID 246, 2019.

[4] M. Dorrigiv, A. Zareiyan, and H. Hosseinzadeh, "Garlic (Allium sativum) as an antidote or a protective agent against natural or chemical toxicities: a comprehensive update review," Phytotherapy Research, vol. 34, no. 8, pp. 1770-1797, 2020.

[5] P. Z. Trio, S. You, X. He, J. He, K. Sakao, and D.-X. Hou, "Chemopreventive functions and molecular mechanisms of garlic organosulfur compounds," Food \& Function, vol. 5, no. 5, pp. $833-844,2014$.

[6] H. He, Y. Ma, H. Huang et al., "A comprehensive understanding about the pharmacological effect of diallyl disulfide other than its anti-carcinogenic activities," European Journal of Pharmacology, vol. 893, Article ID 173803, 2021.

[7] D. De Greef, E. M. Barton, E. N. Sandberg et al., "Anticancer potential of garlic and its bioactive constituents: a systematic and comprehensive review," Seminars in Cancer Biology, vol. 73, pp. 219-264, 2021. 
[8] L. Yi and Q. Su, "Molecular mechanisms for the anti-cancer effects of diallyl disulfide," Food and Chemical Toxicology, vol. 57, pp. 362-370, 2013.

[9] H. Zhang, C. Shang, Z. Tian et al., "Diallyl disulfide suppresses inflammatory and oxidative machineries following carrageenan injection-induced paw edema in mice," Mediators of Inflammation, vol. 2020, Article ID 8508906, 11 pages, 2020.

[10] R. Medzhitov, "Origin and physiological roles of inflammation," Nature, vol. 454, no. 7203, pp. 428-435, 2008.

[11] C. Nathan, "Points of control in inflammation," Nature, vol. 420, no. 6917, pp. 846-852, 2002.

[12] K. L. Flannigan, T. A. Agbor, J. P. Motta et al., "Proresolution effects of hydrogen sulfide during colitis are mediated through hypoxia-inducible factor-1 $\alpha$," The FASEB Journal, vol. 29, no. 4, pp. 1591-1602, 2015.

[13] Y. Chen, R. Xue, X. Jin, and X. Tan, "Antiarthritic activity of diallyl disulfide against freund's adjuvant-induced arthritic rat model," Journal of Environmental Pathology, Toxicology and Oncology, vol. 37, no. 4, pp. 291-303, 2018.

[14] M. Mathan Kumar and R. Tamizhselvi, "Protective effect of diallyl disulfide against cerulein-induced acute pancreatitis and associated lung injury in mice," International Immunopharmacology, vol. 80, pp. 106-136, 2020.

[15] I. Fasolino, A. A. Izzo, T. Clavel, B. Romano, D. Haller, and F. Borrelli, "Orally administered allyl sulfides from garlic ameliorate murine colitis," Molecular Nutrition \& Food Research, vol. 59, no. 3, pp. 434-442, 2015.

[16] Y. Hashizume, K. Shirato, I. Abe et al., "Diallyl disulfide reduced dose-dependently the number of lymphocyte subsets and monocytes in rats," Journal of Nutritional Science \& Vitaminology, vol. 58, no. 4, pp. 292-296, 2012.

[17] K. Bahrampour Juybari, T. Kamarul, M. Najafi, D. Jafari, and A. M. Sharifi, "Restoring the IL- $1 \beta / \mathrm{NF}-\kappa \mathrm{B}$-induced impaired chondrogenesis by diallyl disulfide in human adipose-derived mesenchymal stem cells via attenuation of reactive oxygen species and elevation of antioxidant enzymes," Cell and Tissue Research, vol. 373, no. 2, pp. 407-419, 2018.

[18] I.-C. Lee, S.-H. Kim, H.-S. Baek et al., "The involvement of Nrf2 in the protective effects of diallyl disulfide on carbon tetrachloride-induced hepatic oxidative damage and inflammatory response in rats," Food and Chemical Toxicology, vol. 63, pp. 174-185, 2014.

[19] S. M. Saud, W. Li, Z. Gray et al., "Diallyl disulfide (DADS), a constituent of garlic, inactivates NF- $\kappa \mathrm{B}$ and prevents colitisinduced colorectal cancer by inhibiting GSK-3 $\beta$," Cancer Prevention Research, vol. 9, no. 7, pp. 607-615, 2016.

[20] H. F. Lu, J. S. Yang, Y. T. Lin et al., "Diallyl disulfide induced signal transducer and activator of transcription 1 expression in human colon cancer colo 205 cells using differential display RT-PCR," Cancer genomics \& proteomics, vol. 4, no. 2, pp. 93-97, 2007.

[21] J. Yang, R. Tang, J. Yi et al., "Diallyl disulfide alleviates inflammatory osteolysis by suppressing osteoclastogenesis via NF- $\kappa$ B-NFATc1 signal pathway," The FASEB Journal, vol. 33, no. 6, pp. 7261-7273, 2019.

[22] C. C. Chu, W. S. Wu, J. P. Shieh, H. L Chu, C. P Lee, and P. D Duh, "The anti-inflammatory and vasodilating effects of three selected dietary organic sulfur compounds from allium species," Journal of Functional Biomaterials, vol. 8, no. 1, Article ID 5, 2017.

[23] H.-P. Chang and Y.-H. Chen, "Differential effects of organosulfur compounds from garlic oil on nitric oxide and prostaglandin E2 in stimulated macrophages," Nutrition, vol. 21, no. 4, pp. 530-536, 2005.
[24] J. D. Bailey, M. Diotallevi, T. Nicol et al., "Nitric oxide modulates metabolic remodeling in inflammatory macrophages through TCA cycle regulation and itaconate accumulation," Cell Reports, vol. 28, no. 1, pp. 218-230, 2019.

[25] J. MacMicking, Q.-w. Xie, and C. Nathan, "Nitric oxide and macrophage function," Annual Review of Immunology, vol. 15, no. 1, pp. 323-350, 1997.

[26] H. Y. Park, N. D. Kim, G.-Y. Kim et al., "Inhibitory effects of diallyl disulfide on the production of inflammatory mediators and cytokines in lipopolysaccharide-activated BV2 microglia," Toxicology and Applied Pharmacology, vol. 262, no. 2, pp. 177-184, 2012.

[27] X. Xu, P. Hu, Y. Ma et al., "Identification of a pro-elongation effect of diallyl disulfide, a major organosulfur compound in garlic oil, on microglial process," Journal of Nutritional Biochemistry, vol. 78, Article ID 108323, 2020.

[28] D. A. Locatelli, M. A. Nazareno, C. M. Fusari, and A. B. Camargo, "Cooked garlic and antioxidant activity: correlation with organosulfur compound composition," Food Chemistry, vol. 220, pp. 219-224, 2017.

[29] H.-J. Jang, H.-J. Lee, D.-K. Yoon, D.-S. Ji, J.-H. Kim, and C.-H. Lee, "Antioxidant and antimicrobial activities of fresh garlic and aged garlic by-products extracted with different solvents," Food Science and Biotechnology, vol. 27, no. 1, pp. 219-225, 2018.

[30] Y. Liu, A. Li, X. Feng, X Sun, X Zhu, and Z Zhao, "Pharmacological investigation of the anti-inflammation and antioxidation activities of diallyl disulfide in a rat emphysema model induced by cigarette smoke extract," Nutrients, vol. 10, no. 1, Article ID 79, 2018.

[31] C. Feng, Y. Luo, Y. Nian et al., "Diallyl disulfide suppresses the inflammation and apoptosis resistance induced by DCA through ROS and the NF- $\kappa$ B signaling pathway in human barrett's epithelial cells," Inflammation, vol. 40, no. 3, pp. 818-831, 2017.

[32] G. Filomeni, K. Aquilano, G. Rotilio, and M. R. Ciriolo, "Reactive oxygen species-dependent c-Jun NH2-terminal kinase/c-Jun signaling cascade mediates neuroblastoma cell death induced by diallyl disulfide," Cancer Research, vol. 63, no. 18, pp. 5940-5949, 2003.

[33] X. J. Wu, F. Kassie, and V. Mersch-Sundermann, "The role of reactive oxygen species (ROS) production on diallyl disulfide (DADS) induced apoptosis and cell cycle arrest in human A549 lung carcinoma cells," Mutation Research, vol. 579, no. 1-2, pp. 115-124, 2005.

[34] H.-K. Na, E.-H. Kim, M.-A. Choi, J.-M. Park, D.-H. Kim, and Y.-J. Surh, "Diallyl trisulfide induces apoptosis in human breast cancer cells through ROS-mediated activation of JNK and AP-1," Biochemical Pharmacology, vol. 84, no. 10, pp. 1241-1250, 2012.

[35] W.-W. Kuo, W.-J. Wang, C.-Y. Tsai, C.-L. Way, H.-H. Hsu, and L.-M. Chen, "Diallyl trisufide (DATS) suppresses high glucose-induced cardiomyocyte apoptosis by inhibiting $\mathrm{JNK} / \mathrm{NF} \kappa \mathrm{B}$ signaling via attenuating ROS generation," International Journal of Cardiology, vol. 168, no. 1, pp. 270-280, 2013.

[36] S.-H. Koh, H. Kwon, K. H. Park et al., "Protective effect of diallyl disulfide on oxidative stress-injured neuronally differentiated PC12 cells," Molecular Brain Research, vol. 133, no. 2, pp. 176-186, 2005.

[37] J. G. Kim, S. H. Koh, Y. J. Lee et al., "Differential effects of diallyl disulfide on neuronal cells depend on its concentration," Toxicology, vol. 211, no. 1-2, pp. 86-96, 2005. 
[38] V. Krajka-Kuźniak, J. Paluszczak, and W. Baer-Dubowska, "The Nrf2-ARE signaling pathway: an update on its regulation and possible role in cancer prevention and treatment," Pharmacological Reports, vol. 69, no. 3, pp. 393-402, 2017.

[39] J.-M. Lee and J. A. Johnson, "An important role of Nrf2-ARE pathway in the cellular defense mechanism," BMB Reports, vol. 37, no. 2, pp. 139-143, 2004.

[40] T. Zeng, C.-L. Zhang, F.-Y. Song et al., "The activation of HO-1/Nrf-2 contributes to the protective effects of diallyl disulfide (DADS) against ethanol-induced oxidative stress," Biochimica et Biophysica Acta (BBA) - General Subjects, vol. 1830, no. 10, pp. 4848-4859, 2013.

[41] I.-S. Shin, J. Hong, C.-M. Jeon et al., "Diallyl-disulfide, an organosulfur compound of garlic, attenuates airway inflammation via activation of the Nrf-2/HO-1 pathway and NF-kappaB suppression," Food and Chemical Toxicology, vol. 62, pp. 506-513, 2013.

[42] W. Jin, H. Wang, W. Yan et al., "Disruption of Nrf2 enhances upregulation of nuclear factor-kappaB activity, proinflammatory cytokines, and intercellular adhesion molecule- 1 in the brain after traumatic brain injury," Mediators of Inflammation, vol. 2008, Article ID 725174, 7 pages, 2008.

[43] N. Horn, G. Miller, K. M. Ajuwon, and O. Adeola, "Garlic diallyl disulfide and diallyl trisulfide mitigates effects of prooxidant induced cellular stress and has immune modulatory function in LPS-stimulated porcine epithelial cells," Journal of Animal Science, vol. 95, no. 9, pp. 4045-4051, 2017.

[44] Q. Liu, X. Meng, Y. Li, C. N Zhao, G. Y Tang, and H. B Li, "Antibacterial and antifungal activities of spices," International Journal of Molecular Sciences, vol. 18, no. 6, Article ID 1283, 2017.

[45] Q. Liu, X. Meng, Y. Li et al., "Natural products for the prevention and management of Helicobacter pylori infection," Comprehensive Reviews in Food Science and Food Safety, vol. 17, no. 4, pp. 937-952, 2018.

[46] T. Bjarnsholt, P. Ø Jensen, T. B. Rasmussen et al., "Garlic blocks quorum sensing and promotes rapid clearing of pulmonary Pseudomonas aeruginosa infections," Microbiology (Reading), vol. 151, no. Pt 12, pp. 3873-3880, 2005.

[47] W. R. Li, Y. K. Ma, X. B. Xie et al., "Diallyl disulfide from garlic oil inhibits Pseudomonas aeruginosa quorum sensing systems and corresponding virulence factors," Frontiers in Microbiology, vol. 9, Article ID 3222, 2019.

[48] W.-R. Li, Y.-K. Ma, Q.-S. Shi et al., "Diallyl disulfide from garlic oil inhibits Pseudomonas aeruginosa virulence factors by inactivating key quorum sensing genes," Applied Microbiology and Biotechnology, vol. 102, no. 17, pp. 7555-7564, 2018.

[49] W. R. Li, T. H. Zeng, J. W. Yao et al., "Diallyl sulfide from garlic suppresses quorum-sensing systems of Pseudomonas aeruginosa and enhances biosynthesis of three B vitamins through its thioether group," Microbial Biotechnology, vol. 14, no. 2, pp. 677-691, 2021.

[50] H. Hongman, W. Yifang, Z. Gongliang et al., "Effects of sulfide flavors on AHL-mediated quorum sensing and biofilm formation ofHafnia alvei," Journal of Food Science, vol. 83, no. 10, pp. 2550-2559, 2018.

[51] S. M. Tsao, W. H. Liu, and M. C. Yin, "Two diallyl sulphides derived from garlic inhibit meticillin-resistant Staphylococcus aureus infection in diabetic mice," Journal of Medical Microbiology, vol. 56, no. Pt 6, pp. 803-808, 2007.

[52] S. Casella, M. Leonardi, B. Melai, F. Fratini, and L. Pistelli, "The role of diallyl sulfides and dipropyl sulfides in the in vitro antimicrobial activity of the essential oil of garlic,
Allium sativum L., and leek, Allium porrum L," Phytotherapy Research, vol. 27, no. 3, pp. 380-383, 2013.

[53] P. D. Maldonado, M. E. Chánez-Cárdenas, and J. PedrazaChaverrí, "Aged garlic extract, garlic powder extract, S-allylcysteine, diallyl sulfide and diallyl disulfide do not interfere with the antibiotic activity of gentamicin," Phytotherapy Research, vol. 19, no. 3, pp. 252-254, 2005.

[54] W.-h. Liu, C.-c. Hsu, and M.-c. Yin, "In vitro anti-Helicobacter pylori activity of diallyl sulphides and protocatechuic acid," Phytotherapy Research, vol. 22, no. 1, pp. 53-57, 2008.

[55] J. G. Chung, G. W. Chen, L. T. Wu et al., "Effects of garlic compounds diallyl sulfide and diallyl disulfide on arylamine $\mathrm{N}$-acetyltransferase activity in strains of Helicobacter pylori from peptic ulcer patients," American Journal of Chinese Medicine, vol. 26, no. 3-4, pp. 353-364, 1998.

[56] L. Uzun, T. Dal, M. T. Kalcioglu, M. Yurek, Z. Cibali Acikgoz, and R. Durmaz, "Antimicrobial activity of garlic derivatives on common causative microorganisms of the external ear canal and chronic middle ear infections," Turkish Archives of Otolaryngology, vol. 57, no. 4, pp. 161165, 2019.

[57] R. W. Blackler, J.-P. Motta, A. Manko et al., "Hydrogen sulphide protects against NSAID-enteropathy through modulation of bile and the microbiota," British Journal of Pharmacology, vol. 172, no. 4, pp. 992-1004, 2015.

[58] Y. Yang, F. Yang, M. Huang et al., "Fatty liver and alteration of the gut microbiome induced by diallyl disulfide," International Journal of Molecular Medicine, vol. 44, no. 5, pp. 1908-1920, 2019.

[59] M. Alam, S. Zubair, M. Farazuddin et al., "Development, characterization and efficacy of niosomal diallyl disulfide in treatment of disseminated murine candidiasis," Nanomedicine: Nanotechnology, Biology and Medicine, vol. 9, no. 2, pp. 247-256, 2013.

[60] S. Kocić-Tanackov, G. Dimić, J. Lević et al., "Effects of onion (Allium cepa L.) and garlic (Allium sativum L.) essential oils on the Aspergillus versicolor growth and sterigmatocystin production," Journal of Food Science, vol. 77, no. 5, pp. M278-M284, 2012.

[61] S. Shoji, K. Furuishi, R. Yanase, T. Miyazaka, and M. Kino, "Allyl compounds selectively killed human immunodeficiency virus (type 1)-infected cells," Biochemical and Biophysical Research Communications, vol. 194, no. 2, pp. 610-621, 1993.

[62] A. Hall, A. Troupin, B. Londono-Renteria, and T. M. Colpitts, "Garlic organosulfur compounds reduce inflammation and oxidative stress during dengue virus infection," Viruses, vol. 9, no. 7, Article ID 159, 2017.

[63] M. M. Donma and O. Donma, "The effects of allium sativum on immunity within the scope of COVID-19 infection," Medical Hypotheses, vol. 144, Article ID 109934, 2020.

[64] R. Rouf, S. J. Uddin, D. K. Sarker et al., “Antiviral potential of garlic (Allium sativum) and its organosulfur compounds: a systematic update of pre-clinical and clinical data," Trends in Food Science \& Technology, vol. 104, pp. 219-234, 2020.

[65] B. T. P. Thuy, T. T. A. My, N. T. T. Hai et al., "Investigation into SARS-CoV-2 resistance of compounds in garlic essential oil,” ACS Omega, vol. 5, no. 14, pp. 8312-8320, 2020.

[66] D. J. Marmitt, M. I. Goettert, and C. Rempel, "Compounds of plants with activity against SARS-CoV-2 targets," Expert Review of Clinical Pharmacology, vol. 14, no. 5, pp. 623-633, 2021. 
[67] L. Uzun, N. Kokten, O. H. Cam et al., "The effect of garlic derivatives (S-allylmercaptocysteine, diallyl disulfide, and S-allylcysteine) on gentamicin induced ototoxicity: an experimental study," Clinical and Experimental Otorhinolaryngology, vol. 9, no. 4, pp. 309-313, 2016.

[68] J. Pedraza-Chaverrí, A. E. González-Orozco, P. D. Maldonado, D. Barrera, O. N. Medina-Campos, and R. Hernández-Pandob, "Diallyl disulfide ameliorates gentamicin-induced oxidative stress and nephropathy in rats," European Journal of Pharmacology, vol. 473, no. 1, pp. 71-78, 2003.

[69] J. P. Chiarandini Fiore, S. L. Fanelli, E. C. de Ferreyra, and J. A. Castro, "Diallyl disulfide prevention of cis-diammine dichloroplatinum-induced nephrotoxicity and leukopenia in rats: potential adjuvant effects," Nutrition and Cancer, vol. 60, no. 6, pp. 784-791, 2008.

[70] I.-C. Lee, S.-H. Kim, H.-S. Baek et al., "Protective effects of diallyl disulfide on carbon tetrachloride-induced hepatotoxicity through activation of Nrf2," Environmental Toxicology, vol. 30, no. 5, pp. 538-548, 2015.

[71] S. H. Kim, I. C. Lee, J. W. Ko et al., "Diallyl disulfide prevents cyclophosphamide-induced hemorrhagic cystitis in rats through the inhibition of oxidative damage, MAPKs, and NF- $\kappa \mathrm{B}$ pathways," Biomolecules \& Therapeutics, vol. 23, no. 2, pp. 180-188, 2015.

[72] S.-H. Kim, I.-C. Lee, H.-S. Baek et al., "Mechanism for the protective effect of diallyl disulfide against cyclophosphamide acute urotoxicity in rats," Food and Chemical Toxicology, vol. 64, pp. 110-118, 2014.

[73] S.-H. Kim, I.-C. Lee, H.-S. Baek et al., "Induction of cytochrome P450 3A1 expression by diallyl disulfide: protective effects against cyclophosphamide-induced embryo-fetal developmental toxicity," Food and Chemical Toxicology, vol. 69, pp. 312-319, 2014.

[74] E. Hassanein, W. R. Mohamed, M. M. Khalaf, A. G. S. Shalkami, A. M. Sayed, and R. A. M. Hemeida, "Diallyl disulfide ameliorates methotrexate-induced nephropathy in rats: molecular studies and network pharmacology analysis," Journal of Food Biochemistry, vol. 45, no. 6, Article ID e13765, 2021.

[75] D. Guyonnet, M.-H. Siess, A.-M. Le Bon, and M. Suschetet, "Modulation of phase II enzymes by organosulfur compounds from allium vegetables in rat tissues," Toxicology and Applied Pharmacology, vol. 154, no. 1, pp. 50-58, 1999.

[76] T. Fukao, T. Hosono, S. Misawa, T. Seki, and T. Ariga, "Chemoprotective effect of diallyl trisulfide from garlic against carbon tetrachloride-induced acute liver injury of rats," BioFactors (Oxford, England), vol. 21, no. 1-4, pp. 171-174, 2004.

[77] C.-W. Tsai, H.-W. Chen, J.-J. Yang, L.-Y. Sheen, and C.-K. Lii, "Diallyl disulfide and diallyl trisulfide up-regulate the expression of the $\pi$ class of glutathione S-transferase via an AP-1-dependent pathway," Journal of Agricultural and Food Chemistry, vol. 55, no. 3, pp. 1019-1026, 2007.

[78] C. R. Morris, S. C. Chen, L. Zhou, L. M. Schopfer, X. Ding, and S. S. Mirvish, "Inhibition by allyl sulfides and phenethyl isothiocyanate of methyl-n-pentylnitrosamine depentylation by rat esophageal microsomes, human and rat CYP2E1, and Rat CYP2A3," Nutrition and Cancer, vol. 48, no. 1, pp. 54-63, 2004.

[79] D. M. Davenport and M. J. Wargovich, "Modulation of cytochrome P450 enzymes by organosulfur compounds from garlic," Food and Chemical Toxicology, vol. 43, no. 12, pp. 1753-1762, 2005.
[80] Y. Shan, Z. Wei, L. Tao et al., "Prophylaxis of diallyl disulfide on skin carcinogenic model via p21-dependent Nrf2 stabilization," Scientific Reports, vol. 6, Article ID 35676, 2016.

[81] Y. M. Nkrumah-Elie, J. S. Reuben, A. M. Hudson et al., "The attenuation of early benzo(a)pyrene-induced carcinogenic insults by diallyl disulfide (DADS) in MCF-10A cells," Nutrition and Cancer, vol. 64, no. 7, pp. 1112-1121, 2012.

[82] J. G. Lin, G. W. Chen, C. C. Su et al., "Effects of garlic components diallyl sulfide and diallyl disulfide on arylamine $\mathrm{N}$-acetyltransferase activity and 2-aminofluorene-DNA adducts in human promyelocytic leukemia cells," American Journal of Chinese Medicine, vol. 30, no. 2-3, pp. 315-325, 2002.

[83] F.-S. Yu, C.-S. Yu, J.-P. Lin, S.-C. Chen, W.-W. Lai, and J.-G. Chung, "Diallyl disulfide inhibits $\mathrm{N}$-acetyltransferase activity and gene expression in human esophagus epidermoid carcinoma CE 81T/VGH cells," Food and Chemical Toxicology, vol. 43, no. 7, pp. 1029-1036, 2005.

[84] J. S. Kwak, J. Y. Kim, J. E. Paek et al., "Garlic powder intake and cardiovascular risk factors: a meta-analysis of randomized controlled clinical trials," Nutrition Research and Practice, vol. 8, no. 6, pp. 644-654, 2014.

[85] L. Schwingshackl, B. Missbach, and G. Hoffmann, "An umbrella review of garlic intake and risk of cardiovascular disease," Phytomedicine, vol. 23, no. 11, pp. 1127-1133, 2016.

[86] P. Thejass and G. Kuttan, "Inhibition of angiogenic differentiation of human umbilical vein endothelial cells by diallyl disulfide (DADS)," Life Sciences, vol. 80, no. 6, pp. 515-521, 2007.

[87] K. Meyer, E. Ueberham, and R. Gebhardt, "Influence of organosulphur compounds from garlic on the secretion of matrix metalloproteinases and their inhibitor TIMP-1 by cultured HUVEC cells," Cell Biology and Toxicology, vol. 20, no. 4, pp. 253-260, 2004.

[88] Z. L. Fan, Z. H. Qi, and Y. Xie, "Effect of diallyl disulfide on the expression and secretion of VEGF in HL-60 cells," Zhonghua Xue Ye Xue Za Zhi, vol. 27, no. 9, pp. 626-629, 2006.

[89] Y. Xie, Z. L. Fan, C. J. Yao, S. Q. Tan, and Y. L. Zhao, "Effect of diallyl disulfide on expression and secretion of VEGF in HL-60 leukemic cells," Zhongguo Shi Yan Xue Ye Xue Za Zhi, vol. 14, no. 2, pp. 212-216, 2006.

[90] O. M. Rusiecka, J. Montgomery, S. Morel et al., "Canonical and non-canonical roles of connexin43 in cardioprotection," Biomolecules, vol. 10, no. 9, Article ID 1225, 2020.

[91] C. Huard, N. Druesne, D. Guyonnet et al., "Diallyl disulfide (DADS) enhances gap-junctional intercellular communication by both direct and indirect mechanisms in rat liver cells," Carcinogenesis, vol. 25, no. 1, pp. 91-98, 2004.

[92] C. N. Joshi, D. N. Martin, P. Shaver, C. Madamanchi, B. J. Muller-Borer, and D. A. Tulis, "Control of vascular smooth muscle cell growth by connexin 43," Frontiers in Physiology, vol. 3, Article ID 220, 2012.

[93] C.-c. Ou, S.-m. Tsao, M.-c. Lin, and M.-c. Yin, "Protective action on human LDL against oxidation and glycation by four organosulfur compounds derived from garlic," Lipids, vol. 38, no. 3, pp. 219-224, 2003.

[94] C.-N. Huang, J.-S. Horng, and M.-C. Yin, “Antioxidative and antiglycative effects of six organosulfur compounds in lowdensity lipoprotein and plasma," Journal of Agricultural and Food Chemistry, vol. 52, no. 11, pp. 3674-3678, 2004.

[95] Y. P. Lei, C. T. Liu, L. Y. Sheen, H. W. Chen, and C. K. Lii, "Diallyl disulfide and diallyl trisulfide protect endothelial nitric oxide synthase against damage by oxidized low-density 
lipoprotein," Molecular Nutrition \& Food Research, vol. 54, no. Suppl 1, pp. S42-S52, 2010.

[96] D. M. Bautista, P. Movahed, A. Hinman et al., "Pungent products from garlic activate the sensory ion channel TRPA1," Proceedings of the National Academy of Sciences, vol. 102, no. 34, pp. 12248-12252, 2005.

[97] S. H. Lee, Y. T. Liu, K. M. Chen, C. K. Lii, and C. T. Liu, "Effect of garlic sulfur compounds on neutrophil infiltration and damage to the intestinal mucosa by endotoxin in rats," Food and Chemical Toxicology: An International Journal Published for the British Industrial Biological Research Association, vol. 50, no. 3-4, pp. 567-574, 2012.

[98] B. M. Park, H. Chun, S. W. Chae, and S. H. Kim, "Fermented garlic extract ameliorates monocrotaline-induced pulmonary hypertension in rats," Journal of Functional Foods, vol. 30, pp. 247-253, 2017.

[99] A. Martelli, L. Testai, V. Citi et al., "Arylthioamides as H2S donors: 1-cysteine-activated releasing properties and vascular effects in vitro and in vivo," ACS Medicinal Chemistry Letters, vol. 4, no. 10, pp. 904-908, 2013.

[100] Y. T. Huang, C. H. Yao, C. L. Way et al., "Diallyl trisulfide and diallyl disulfide ameliorate cardiac dysfunction by suppressing apoptotic and enhancing survival pathways in experimental diabetic rats," Journal of Applied Physiology, vol. 114, no. 3, pp. 402-410, 2013.

[101] T. N. Khatua, A. K. Dinda, U. K. Putcha, and S. K. Banerjee, "Diallyl disulfide ameliorates isoproterenol induced cardiac hypertrophy activating mitochondrial biogenesis via eNOSNrf2-Tfam pathway in rats," Biochemistry and Biophysics Reports, vol. 5, pp. 77-88, 2016.

[102] P. J. O'Brien, A. G. Siraki, and N. Shangari, "Aldehyde sources, metabolism, molecular toxicity mechanisms, and possible effects on human health," Critical Reviews in Toxicology, vol. 35, no. 7, pp. 609-662, 2005.

[103] Y. Su, X. Ma, N. Jiang et al., "Toxic target of trans-crotonaldehyde in mitochondria altered by diallyl disulfides for anti-myocardial ischemia," Spectrochimica Acta Part A: Molecular and Biomolecular Spectroscopy, vol. 205, pp. 568-573, 2018.

[104] M. Iranshahy and B. Javadi, "Diet therapy for the treatment of Alzheimer's disease in view of traditional Persian medicine: a review," Iranian journal of basic medical sciences, vol. 22, no. 10, pp. 1102-1117, 2019.

[105] X. Wei, Y. Ma, F. Li et al., "Acute diallyl disulfide administration prevents and reveres lipopolysaccharide-induced depression-like behaviors in mice via regulating neuroinflammation and oxido-nitrosative stress," Inflammation, vol. 44, no. 4, pp. 1381-1395, 2021.

[106] S. T. Ji, M.-S. Kim, H. R. Park et al., "Diallyl disulfide impairs hippocampal neurogenesis in the young adult brain," Toxicology Letters, vol. 221, no. 1, pp. 31-38, 2013.

[107] G. Wang, Y. Yang, C. Wang et al., "Exploring the role and mechanisms of diallyl trisulfide and diallyl disulfide in chronic constriction-induced neuropathic pain in rats," The Korean Journal of Pain, vol. 33, no. 3, pp. 216-225, 2020.

[108] J. X. Chai, H. H. Li, Y. Y. Wang et al., "Effect of diallyl disulfide on learning and memory abilities and hippocampal synapses in mouse models of Alzheimer's disease," Nan Fang Yi Ke Da Xue Xue Bao, vol. 36, no. 10, pp. 1417-1422, 2016.

[109] A. Manral, P. Meena, V. Saini, F. Siraj, S. Shalini, and M. Tiwari, "DADS analogues ameliorated the cognitive impairments of alzheimer-like rat model induced by scopolamine," Neurotoxicity Research, vol. 30, no. 3, pp. 407-426, 2016.
[110] A. Manral, V. Saini, P. Meena, and M. Tiwari, "Multifunctional novel diallyl disulfide (DADS) derivatives with $\beta$-amyloid-reducing, cholinergic, antioxidant and metal chelating properties for the treatment of Alzheimer's disease," Bioorganic \& Medicinal Chemistry, vol. 23, no. 19, pp. 6389-6403, 2015.

[111] N. B. Chauhan, "Effect of aged garlic extract on APP processing and tau phosphorylation in Alzheimer's transgenic model Tg2576," Journal of Ethnopharmacology, vol. 108, no. 3, pp. 385-394, 2006.

[112] X. Gu and Y. Z. Zhu, "Therapeutic applications of organosulfur compounds as novel hydrogen sulfide donors and/ or mediators," Expert Review of Clinical Pharmacology, vol. 4, no. 1, pp. 123-133, 2011.

[113] D. Y. Shin, G.-Y. Kim, J.-I. Kim et al., "Anti-invasive activity of diallyl disulfide through tightening of tight junctions and inhibition of matrix metalloproteinase activities in LNCaP prostate cancer cells," Toxicology in Vitro, vol. 24, no. 6, pp. 1569-1576, 2010.

[114] H. S. Park, G.-Y. Kim, I.-W. Choi et al., "Inhibition of matrix metalloproteinase activities and tightening of tight junctions by diallyl disulfide in AGS human gastric carcinoma cells," Journal of Food Science, vol. 76, no. 4, pp. T105-T111, 2011.

[115] K.-C. Lai, S.-C. Hsu, C.-L. Kuo et al., "Diallyl sulfide, diallyl disulfide, and diallyl trisulfide inhibit migration and invasion in human colon cancer colo 205 cells through the inhibition of matrix metalloproteinase-2, -7, and -9 expressions," Environmental Toxicology, vol. 28, no. 9, pp. 479-488, 2013.

[116] X. Yin, C. Feng, L. Han et al., "Diallyl disulfide inhibits the metastasis of type II esophageal-gastric junction adenocarcinoma cells via NF- $\kappa \mathrm{B}$ and PI3K/AKT signaling pathways in vitro," Oncology Reports, vol. 39, no. 2, pp. 784-794, 2018.

[117] D. Bauer, E. Mazzio, K. F. Soliman et al., "Diallyl disulfide inhibits TNF $\alpha$-induced CCL2 release by MDA-MB-231 cells," Anticancer Research, vol. 34, no. 6, pp. 2763-2770, 2014.

[118] D. Bauer, N. Redmon, E. Mazzio et al., "Diallyl disulfide inhibits TNF $\alpha$ induced CCL2 release through MAPK/ERK and NF-Kappa-B signaling," Cytokine, vol. 75, no. 1, pp. 117-126, 2015.

[119] D. P. Lavin and V. K. Tiwari, "Unresolved complexity in the gene regulatory network underlying EMT," Frontiers in oncology, vol. 10, Article ID 554, 2020.

[120] B. Su, J. Su, Y. Zeng et al., "Diallyl disulfide inhibits TGF- $\beta 1$ induced upregulation of Racl and $\beta$-catenin in epithelialmesenchymal transition and tumor growth of gastric cancer," Oncology Reports, vol. 39, no. 6, pp. 2797-2806, 2018.

[121] J. Huang, B. Yang, T. Xiang et al., "Diallyl disulfide inhibits growth and metastatic potential of human triple-negative breast cancer cells through inactivation of the $\beta$-catenin signaling pathway," Molecular Nutrition \& Food Research, vol. 59, no. 6, pp. 1063-1075, 2015.

[122] B. Su, J. Su, Y. Zeng et al., "Diallyl disulfide suppresses epithelial-mesenchymal transition, invasion and proliferation by downregulation of LIMK1 in gastric cancer," Oncotarget, vol. 7, no. 9, pp. 10498-10512, 2016.

[123] J. Su, Y. Zhou, Z. Pan et al., "Downregulation of LIMK1$\mathrm{ADF} /$ cofilin by DADS inhibits the migration and invasion of colon cancer," Scientific Reports, vol. 7, p. 45624, 2017.

[124] L. Xia, J. Lin, J. Su et al., "Diallyl disulfide inhibits colon cancer metastasis by suppressing Rac1-mediated epithelialmesenchymal transition," OncoTargets and Therapy, vol. 12, pp. 5713-5728, 2019. 
[125] B. Das and D. Sinha, "Diallyl disulphide suppresses the cannonical Wnt signaling pathway and reverses the fibronectin-induced epithelial mesenchymal transition of A549 lung cancer cells," Food \& Function, vol. 10, no. 1, pp. 191-202, 2019.

[126] R. Liu, Y. N. Yang, L. Yi et al., "Diallyl disulfide effect on the invasion and migration ability of HL-60 cells with a high expression of DJ-1 in the nucleus through the suppression of the Src signaling pathway," Oncology letters, vol. 15, no. 5, pp. 6377-6385, 2018.

[127] J. Zheng, Y. Zhou, Y. Li, D. P. Xu, S. Li, and H. B. Li, "Spices for prevention and treatment of cancers," Nutrients, vol. 8, no. 8, Article ID 495, 2016.

[128] X. Yin, R. Zhang, C. Feng et al., "Diallyl disulfide induces G2/ $M$ arrest and promotes apoptosis through the p53/p21 and MEK-ERK pathways in human esophageal squamous cell carcinoma," Oncology Reports, vol. 32, no. 4, pp. 1748-1756, 2014.

[129] I. A. Ansari, A. Ahmad, M. A. Imran, M. Saeed, and I. Ahmad, "Organosulphur compounds induce apoptosis and cell cycle arrest in cervical cancer cells via downregulation of HPV E6 and E7 oncogenes," Anti-Cancer Agents in Medicinal Chemistry, vol. 21, no. 3, pp. 393-405, 2021.

[130] N. Druesne, A. Pagniez, C. Mayeur et al., "Diallyl disulfide (DADS) increases histone acetylation and p21(waf1/cip1) expression in human colon tumor cell lines," Carcinogenesis, vol. 25, no. 7, pp. 1227-1236, 2004.

[131] N. Druesne-Pecollo, A. Pagniez, M. Thomas et al., "Diallyl disulfide increases CDKN1A promoter-associated histone acetylation in human colon tumor cell lines," Journal of Agricultural and Food Chemistry, vol. 54, no. 20, pp. 75037507, 2006.

[132] C. H. Kuo, Y. L. Leu, T. H. Wang et al., “A novel DNA repair inhibitor, diallyl disulfide (DADS), impairs DNA resection during DNA double-strand break repair by reducing Sae2 and Exo1 levels," DNA Repair, vol. 82, Article ID 102690, 2019.

[133] K. Aquilano, P. Vigilanza, G. Filomeni, G. Rotilio, and M. R. Ciriolo, "Tau dephosphorylation and microfilaments disruption are upstream events of the anti-proliferative effects of DADS in SH-SY5Y cells," Journal of Cellular and Molecular Medicine, vol. 14, no. 3, pp. 564-577, 2010.

[134] G. Pistritto, D. Trisciuoglio, C. Ceci, A. Garufi, and G. D’Orazi, “Apoptosis as anticancer mechanism: function and dysfunction of its modulators and targeted therapeutic strategies," Aging, vol. 8, no. 4, pp. 603-619, 2016.

[135] H.-L. Lin, J.-S. Yang, J.-H. Yang et al., "The role of Ca2+ on the DADS-induced apoptosis in mouse-rat hybrid retina ganglion cells (N18)," Neurochemical Research, vol. 31, no. 3, pp. 383-393, 2006.

[136] R. Gayathri, D. N. Gunadharini, A. Arunkumar et al., "Effects of diallyl disulfide (DADS) on expression of apoptosis associated proteins in androgen independent human prostate cancer cells (PC-3)," Molecular and Cellular Biochemistry, vol. 320, no. 1-2, pp. 197-203, 2009.

[137] V. T. Siddhartha, S. K. S. S. Pindiprolu, P. K. Chintamaneni, S. Tummala, and S. Nandha Kumar, "RAGE receptor targeted bioconjuguate lipid nanoparticles of diallyl disulfide for improved apoptotic activity in triple negative breast cancer: in vitro studies," Artificial Cells, Nanomedicine, and Biotechnology, vol. 46, no. 2, pp. 387-397, 2018.

[138] Y.-S. Hong, Y.-A. Ham, J.-H. Choi, and J. Kim, "Effects of allyl sulfur compounds and garlic extract on the expression of Bcl-2, Bax, and p53 in non small cell lung cancer cell lines," Experimental \& Molecular Medicine, vol. 32, no. 3, pp. 127-134, 2000.

[139] H. J. Kim, S. Kang, D. Y. Kim et al., "Diallyl disulfide (DADS) boosts TRAIL-Mediated apoptosis in colorectal cancer cells by inhibiting Bcl-2," Food and Chemical Toxicology, vol. 125, pp. 354-360, 2019.

[140] Y. Li, S. Li, X. Meng, R. Y Gan, J. J Zhang, and H. B Li, "Dietary natural products for prevention and treatment of breast cancer," Nutrients, vol. 9, no. 7, Article ID 728, 2017.

[141] L. Yi, X.-X. Ji, H. Tan et al., "Role of Ras-related C3 botulinum toxin substrate 2 (Rac2), NADPH oxidase and reactive oxygen species in diallyl disulphide-induced apoptosis of human leukaemia HL-60 cells," Clinical and Experimental Pharmacology and Physiology, vol. 37, no. 12, pp. 1147-1153, 2010.

[142] S. F. T. Agassi, T.-M. Yeh, C.-D. Chang, J.-L. Hsu, and W.-L. Shih, "Potentiation of differentiation and apoptosis in a human promyelocytic leukemia cell line by garlic essential oil and its organosulfur compounds," Anticancer Research, vol. 40, no. 11, pp. 6345-6354, 2020.

[143] G. Filomeni, K. Aquilano, G. Rotilio, and M. R. Ciriolo, "Glutathione-related systems and modulation of extracellular signal-regulated kinases are involved in the resistance of AGS adenocarcinoma gastric cells to diallyl disulfide-induced apoptosis," Cancer Research, vol. 65, no. 24, pp. 11735-11742, 2005.

[144] S. Karmakar, S. Roy Choudhury, N. L. Banik, and S. K. Ray, "Molecular mechanisms of anti-cancer action of garlic compounds in neuroblastoma," Anti-Cancer Agents in Medicinal Chemistry, vol. 11, no. 4, pp. 398-407, 2011.

[145] C. Di, C. Sun, H. Li et al., "Diallyl disulfide enhances carbon ion beams-induced apoptotic cell death in cervical cancer cells through regulating Tap73/ANp73," Cell Cycle, vol. 14, no. 23, pp. 3725-3733, 2015.

[146] Y. Wu, Y. Hu, H. Zhou et al., "Organosulfur compounds induce cytoprotective autophagy against apoptosis by inhibiting mTOR phosphorylation activity in macrophages," Acta Biochimica et Biophysica Sinica, vol. 50, no. 11, pp. 1085-1093, 2018.

[147] T. Suangtamai and D. I. Tanyong, "Diallyl disulfide induces apoptosis and autophagy via mTOR pathway in myeloid leukemic cell line," Tumor Biology, vol. 37, no. 8, pp. 10993-10999, 2016.

[148] Z. Yue, X. Guan, R. Chao et al., "Diallyl disulfide induces apoptosis and autophagy in human osteosarcoma MG-63 cells through the PI3K/Akt/mTOR pathway," Molecules, vol. 23, no. 14, 2019.

[149] A. Choromanska, J. Kulbacka, J. Saczko, and P. Surowiak, "Effect of diallyl disulfide and garlic oil on different human astrocytoma cell lines," Biomedical reports, vol. 13, no. 4, p. 32, 2020.

[150] J. Zhang, S. Ng, J. Wang et al., "Histone deacetylase inhibitors induce autophagy through FOXO1-dependent pathways," Autophagy, vol. 11, no. 4, pp. 629-642, 2015.

[151] H. Ling, J. He, H. Tan et al., "Identification of potential targets for differentiation in human leukemia cells induced by diallyl disulfide," International Journal of Oncology, vol. 50, no. 2, pp. 697-707, 2017.

[152] Q. Li, Y. Tang, J. Qin et al., "Subcellular localization of DJ-1 in human HL-60 leukemia cells in response to diallyl disulfide treatment," Molecular Medicine Reports, vol. 14, no. 5, pp. 4666-4672, 2016. 
[153] L. Yi, J. Shan, X. Chen et al., "Involvement of calreticulin in cell proliferation, invasion and differentiation in diallyl disulfide-treated HL-60 cells," Oncology Letters, vol. 12, no. 3, pp. 1861-1867, 2016.

[154] J. Sun, H. Mu, J. Yu et al., "Diallyl disulfide down-regulates calreticulin and promotes $\mathrm{C} / \mathrm{EBP} \alpha$ expression in differentiation of human leukaemia cells," Journal of Cellular and Molecular Medicine, vol. 23, no. 1, pp. 194-204, 2019.

[155] J. Zhao, W.-g. Huang, J. He, H. Tan, Q.-j. Liao, and Q. Su, "Diallyl disulfide suppresses growth of HL-60 cell through increasing histone acetylation and p21WAF1expression in vivo and in vitro," Acta Pharmacologica Sinica, vol. 27, no. 11, pp. 1459-1466, 2006.

[156] J. S. Yang, L. F. Kok, Y. H. Lin et al., "Diallyl disulfide inhibits WEHI-3 leukemia cells in vivo," Anticancer Research, vol. 26, no. 1A, pp. 219-225, 2006.

[157] M. A. Lea and V. M. Randolph, "Induction of histone acetylation in rat liver and hepatoma by organosulfur compounds including diallyl disulfide," Anticancer Research, vol. 21, no. 4A, pp. 2841-2845, 2001.

[158] N. Druesne-Pecollo, C. Chaumontet, and P. Latino-Martel, "Diallyl disulfide increases histone acetylation in colon cells in vitro and in vivo," Nutrition Reviews, vol. 66, no. Suppl 1, pp. S39-S41, 2008.

[159] N. Druesne, A. Pagniez, C. Mayeur et al., "Repetitive treatments of colon HT-29 cells with diallyl disulfide induce a prolonged hyperacetylation of histone H3 K14," Annals of the New York Academy of Sciences, vol. 1030, no. 1, pp. 612-621, 2004.

[160] M. O. Altonsy, T. N. Habib, and S. C. Andrews, "Diallyl disulfide-induced apoptosis in a breast-cancer cell line (MCF-7) may be caused by inhibition of histone deacetylation," Nutrition and Cancer, vol. 64, no. 8, pp. 1251-1260, 2012.

[161] Y. Hashizume, K. Shirato, S. Sato, A. Matsumoto, K. Tachiyashiki, and K. Imaizumi, "Dose-dependent effects of diallyl disulfide on plasma glucose and free fatty acid levels in rats," Journal of Toxicological Sciences, vol. 38, no. 6, pp. 879-884, 2013.

[162] C.-T. Liu, P.-L. Wong, C.-K. Lii, H. Hse, and L.-Y. Sheen, "Antidiabetic effect of garlic oil but not diallyl disulfide in rats with streptozotocin-induced diabetes," Food and Chemical Toxicology, vol. 44, no. 8, pp. 1377-1384, 2006.

[163] X. Xie, X. Huang, H. Tang et al., "Diallyl disulfide inhibits breast cancer stem cell progression and glucose metabolism by targeting CD44/PKM2/AMPK signaling," Current Cancer Drug Targets, vol. 18, no. 6, pp. 592-599, 2018.

[164] J. Bae, M. Kumazoe, Y. Fujimura, and H. Tachibana, "Diallyl disulfide potentiates anti-obesity effect of green tea in highfat/high-sucrose diet-induced obesity," The Journal of $\mathrm{Nu}$ tritional Biochemistry, vol. 64, pp. 152-161, 2019.

[165] N. Zhang, Y. Wang, J. Zhang et al., "Diallyl disulfide attenuates non-alcoholic steatohepatitis by suppressing key regulators of lipid metabolism, lipid peroxidation and inflammation in mice," Molecular Medicine Reports, vol. 20, no. 2, pp. 1363-1372, 2019.

[166] S. K. Rai, M. Sharma, and M. Tiwari, "Inhibitory effect of novel diallyldisulfide analogs on HMG-CoA reductase expression in hypercholesterolemic rats: CREB as a potential upstream target," Life Sciences, vol. 85, no. 5-6, pp. 211-219, 2009.

[167] H.-M. Woo, J.-H. Kang, T. Kawada, H. Yoo, M.-K. Sung, and $\mathrm{R}$. $\mathrm{Yu}$, "Active spice-derived components can inhibit inflammatory responses of adipose tissue in obesity by suppressing inflammatory actions of macrophages and release of monocyte chemoattractant protein-1 from adipocytes," Life Sciences, vol. 80, no. 10, pp. 926-931, 2007.

[168] N. L. Horn, F. Ruch, G. Miller, K. M. Ajuwon, and O. Adeola, "Determination of the adequate dose of garlic diallyl disulfide and diallyl trisulfide for effecting changes in growth performance, total-tract nutrient and energy digestibility, ileal characteristics, and serum immune parameters in broiler chickens," Poultry Science, vol. 95, no. 10, pp. 2360-2365, 2016.

[169] S. R. Musk, P. Clapham, and I. T. Johnson, "Cytotoxicity and genotoxicity of diallyl sulfide and diallyl disulfide towards Chinese hamster ovary cells," Food and Chemical Toxicology: An International Journal Published for the British Industrial Biological Research Association, vol. 35, no. 3-4, pp. 379-385, 1997.

[170] M. Thomas, P. Zhang, M.-L. Noordine, P. Vaugelade, C. Chaumontet, and P.-H. Duée, "Diallyl disulfide increases rat h-ferritin, l-ferritin and transferrin receptor genes in vitro in hepatic cells and in vivo in liver," Journal of Nutrition, vol. 132, no. 12, pp. 3638-3641, 2002.

[171] M. Koushki, N. Amiri-Dashatan, Y. Pourfarjam, and A. H. Doustimotlagh, "Effect of garlic intake on inflammatory mediators: a systematic review and meta-analysis of randomised controlled trials," Postgraduate Medical Journal, vol. 97, no. 1145, pp. 156-163, 2021.

[172] Z. Farhat, P. A. Hershberger, J. L. Freudenheim et al., "Types of garlic and their anticancer and antioxidant activity: a review of the epidemiologic and experimental evidence," European Journal of Nutrition, vol. 60, no. 7, pp. 3585-3609, 2021.

[173] M. Askari, H. Mozaffari, M. Darooghegi Mofrad et al., "Effects of garlic supplementation on oxidative stress and antioxidative capacity biomarkers: a systematic review and meta-analysis of randomized controlled trials," Phytotherapy Research, vol. 35, no. 6, pp. 3032-3045, 2021.

[174] A. G. Atanasov, S. B. Zotchev, S. B. Zotchev, V. M. Dirsch, and C. T. Supuran, "Natural products in drug discovery: advances and opportunities," Nature Reviews Drug Discovery, vol. 20, no. 3, pp. 200-216, 2021.

[175] D. Kashyap, H. S. Tuli, M. B. Yerer et al., "Natural productbased nanoformulations for cancer therapy: opportunities and challenges," Seminars in Cancer Biology, vol. 69, pp. 5-23, 2021. 